\title{
REAKTUALISASI KONSEP IDDAH DALAM PERNIKAHAN
}

\author{
Henderi Kusmidi \\ Lembaga Penjaminan Mutu IAIN Bengkulu \\ Jl. Raden Fatah Pagar Dewa Bengkulu \\ Email: hendri.kusmidi@gmail.com
}

\begin{abstract}
God has ordained the waiting period, the waiting period because there is some wisdom that is priceless and is a source of life such regularity is as if in the woman's assertion that still contained the seeds of the fetus or not, so that later nasabnya not stir. Similarly, to give them an opportunity to refer to her husband and aware of the excesses of blindly, having thought out and considered deeply. Also the waiting period, it will be seen how the mercy of God to man, because the wait was going to find out how good a person is married or unmarried, and how unfortunately divorce so that the act was lawful but hated by Allah. The waiting period for a woman who left her husband dead, then it is a time when it appeared in mourning, so that increasingly felt tribute to her husband.
\end{abstract}

Keywords: Marriage, iddah, Islamic law

\begin{abstract}
Abstrak: Allah Swt telah mensyari'atkan iddah, karena dalam iddah itu terdapat beberapa hikmah yang tak ternilai harganya dan merupakan salah satu sumber keteraturan hidup antara lain adalah sebagai penegasan apakah dalam rahim wanita itu masih terkandung benih janin atau tidak, sehingga nasabnya nanti tidak kacau. Begitu pula untuk memberi kesempatan kepada suami mau rujuk kepada isterinya dan sadar akan keterlanjurannya yang membabi buta, setelah dipikirkan dan dipertimbangkan dalam-dalam. Dengan iddah itu juga akan semakin nampak betapa belas kasihan Allah kepada manusia, karena dalam menunggu itu orang akan mengetahui betapa nikmatnya bersuami atau beristeri, dan betapa malangnya perceraian sehingga perbuatan itu halal tetapi dibenci Allah Swt. Iddah bagi isteri yang ditinggal mati suaminya, maka di waktu itu ia lebih nampak berkabung, sehingga semakin terasa penghormatannya terhadap suaminya.
\end{abstract}

Kata kunci: Pernikahan, iddah, hukum Islam

\section{Pendahuluan}

Dalam pandangan Islam pernikahan merupakan aturan Allah Swt dan sunnah Rasulullah saw. Aturan Allah berarti menurut qudrah dan iradah Allah dalam penciptaan alam ini, sedangkan sunnah Rasul berarti suatu tradisi yang telah ditetapkan oleh Rasul untuk dirinya sendiri dan umatnya. Oleh sebab itu, pernikahan merupakan hal yang sakral, suci, luhur dan dijunjung tinggi oleh masyarakat. Ini merupakan ketentuan dan peraturan Allah untuk melestarikan kehidupan umat manusia di bumi, untuk menjamin kelangsungan eksistensi manusia sebagai khalifah.

Seks merupakan kebutuhan biologis laki- laki terhadap lawan jenisnya atau sebaliknya. Ia merupakan naluri yang kuat serta selalu menuntut untuk dipenuhi. Pemenuhan kebutuhan naluri seks itu hanya bisa dilakukan apabila antara laki-laki dan perempuan telah diikat oleh suatu ikatan yang sah yang disebut dengan pernikahan. Manakala setelah perkawinan terjadi hubungan seks, tetapi dalam perjalanan perkawinan itu ternyata tidak berjalan dengan mulus dan terdapat berbagai halangan dan rintangan yang mengakibatkan tujuan perkawinan itu tidak bisa dicapai dan sebagai puncaknya terjadilah perceraian. Akibat dari adanya perceraian inilah yang menyebabkan adanya kewajiban bagi seorang perempuan untuk beriddah atau dalam istilah lain disebut masa tunggu. 


\section{Pengertian Iddah}

Iddah adalah masa penantian (untuk tidak menikah dulu) bagi seorang istri dalam waktu yang sudah ditentukan oleh agama, yang bertujuan untuk mengetahui kosongnya rahim seorang istri (bagi istri yang masih berpotensi hamil) atau karena peribadatan/ta'abbud/ taken for granted (bagi istri yang masih kecil atau sudah menopause) sebagai bentuk duka cita atas wafatnya suami. Pada mulanya iddah disyariatkankan untuk menjaga turunan dari percampuran sperma. ${ }^{1}$

Iddah bermakna perhitungan atau sesuatu yang di hitung. Secara bahasa mengandung pengertian hari-hari haidh atau hari-hari suci pada wanita. sedangkan secara istilah, " iddah mengandung arti masa menunggu, artinya masa menunggu bagi wanita untuk melakukan perkawinan setelah terjadinya perceraian dengan suaminya, baik cerai hidup maupun cerai mati, dengan tujuan untuk mengetahui keadaan rahimnya atau untuk berfikir bagi suami. ${ }^{2}$

Iddah adalah masa menanti yang diwajibkan atas perempuan yang diceraikan suaminya baik cerai hidup maupun cerai mati guna untuk mengetahui kandungannya berisi atau tidak. Perempuan yang ceraikan suaminya adakalanya hamil dan adakalanya tidak. ${ }^{3}$ Dengan redaksi yang agak panjang Ahmad Al-Ghundur memberikan definisi 'iddah dengan, jenjang waktu yang di tentukan untuk menanti kesucian (kebersihan rahim) dari pengaruh hubungan suami istri setelah sang istri di ceraikan atau ditinggal mati suami, yaitu waktu yang biasa dipikul oleh istri setelah putus ikatan pernikahan karena dikhawatirkan terjadi kesyubhatan dalam pengaruh hubungan kelamin atau yang sesamanya seperti bermesra-mesraan (dengan

1 Sayyid Alawi Bin Sayyid Ahmad As-Segaf, Tarsyihul Mustafidin, (Beirut, Darul Fikr) h. 323-324

2 Abdul Aziz Dahlan (ed) Ensiklopedi Hukum Islam, Jilid II, (Jakarta: Icktiar Baru Van Hoeve, 1996), h. 637.

${ }^{3}$ Diterbitkan oleh Proyek Peningkatan Sarana Keagamaan Islam, Zakat dan Wakaf Direktorat Jenderal Bimas Islam dan Urusan Haji, Pedoman Figh Munakahat, Jakarta, Tahun 1999/2000, h. 33 pria lain jika ia segera menikah). ${ }^{4}$

Kata iddah berasal dari bahasa Arab yang berarti menghitung, menduga, mengira. Menurut istilah, ulama-ulama memberikan pengertian sebagai berikut:

1. Syarbini Khatib dalam kitabnya "Mugnil Muhtaj" mendifinisikan iddah dengan "Iddah adalah nama masa menunggu bagi seorang perempuan untuk mengetahui kekosongan rahimnya atau karena sedih atas meninggal suaminya.

2. Abdul Fatah Idris dan Abu Ahmadi memberikan pengertian iddah dengan "Masa yang tertentu untuk menungu, hingga seorang perempuan diketahui kebersihan rahimnya sesudah bercerai."

3. Abdurrahman I Doi memberikan pengertian iddah ini dengan "suatu masa penantian seorang perempuan sebelum kawin lagi setelah kematian suaminya atau bercerai darinya."

4. Sayyid Sabiq memberikan pengertian dengan "masa lamanya bagi perempuan (istri) menunggu dan tidak boleh kawin setelah kematian suaminya."

5. Arti iddah menurut lughat adalah perhitungan, dan dalam istilah fiqh adalah waktu tunggu bagi wanita yang ditalak atau ditinggal mati suaminya, untuk mengetahui dengan yakin bebas atau tidaknya wanita itu dari hamil atau bagi wanita yang sudah putus haidhnya dimaksudkan semata-mata ta’abbud kepada hukum Allah SWT.

6. Adapun yang dimaksud dengan iddah adalah masa tunggu seorang isteri yang telah diceraikan suaminya dengan talak raj'i atau ditinggal mati suaminya. ${ }^{6}$

Selain pengertian tersebut di atas, banyak lagi pengertian-pengertian lain yang diberikan

\footnotetext{
${ }^{4}$ Ahmad Al-Ghundur, al-Thalaq al-syariat al-Islamiyyah wal al-Qanun, (Mesir: Dar al-Ma'arif, 1997), h. 291.

${ }^{5}$ Moh. Anwar, Fiqh Islam (Muamalah, Munakahat, Faro’id dan Jinayah Beserta Kaidah-Kaidah Hukumnya), (Subang: t.pn, 1988), Cet. ke-2, h. 183.

${ }^{6}$ Ahsin W. Al-Tahfidz, Kamus Ilmu Al-Qur'an, (Jakarta: Penerbit Amzah, 2006) , h. 109.
} 
para ulama, namun pada prinsipnya pengertian tersebut hampir bersamaan maksudnya yaitu diterjemahkan dengan masa tunggu bagi seorang perempuan untuk bisa rujuk lagi dengan bekas suaminya atau batasan untuk boleh kawin lagi.

\section{Dasar Hukum Iddah}

Dalil dari al-Qur’ân antara lain firman Allah Swt:

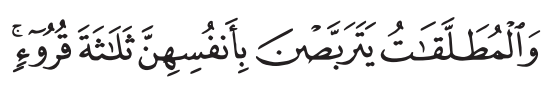

"Wanita-wanita yang ditalak handaklah menahan diri (menunggu) tiga kali quru' (Q.S.alBaqarah/2:228)

Dalam ayat lain Allah berfirman pada surat al-Thalaq ayat: 1

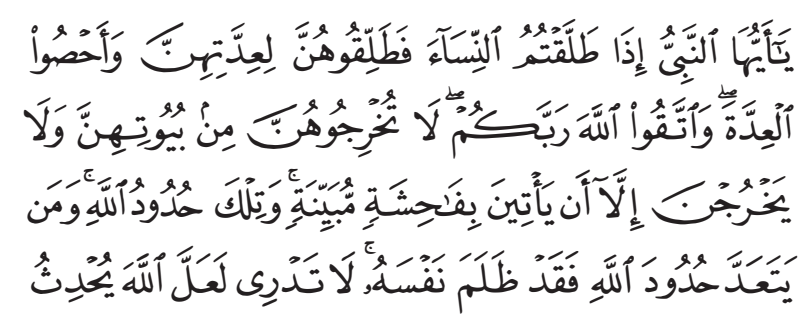



"Hai Nabi, apabila kamu menceraikan istriistrimu maka hendaklah kamu ceraikan mereka pada waktu mereka dapat (menghadapi) idahnya (yang wajar) dan hitunglah waktu idah itu serta bertakwalah kepada Allah Tuhanmu. Janganlah kamu keluarkan mereka dari rumah mereka dan janganlah mereka (diizinkan) ke luar kecuali kalau mereka mengerjakan perbuatan keji yang terang. Itulah hukum-hukum Allah dan barang siapa yang melanggar hukum-hukum Allah, maka sesungguhnya dia telah berbuat lalim terhadap dirinya sendiri. Kamu tidak mengetahui barangkali Allah mengadakan sesudah itu suatu halyang baru".

Sedangkan dalil dari sunnah, banyak sekali di antaranya:

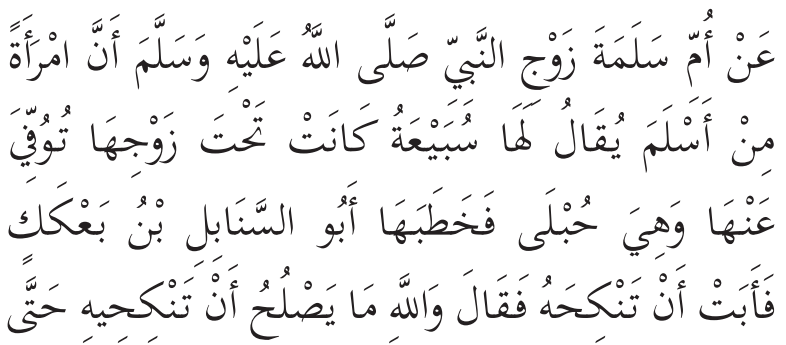

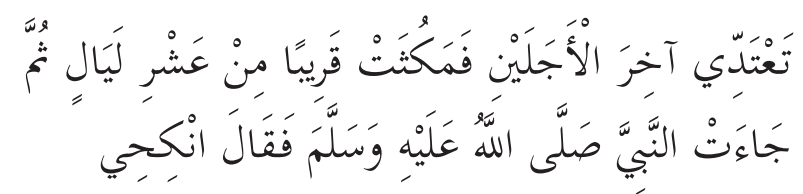

Dari Ummu Salamah istri Nabi saw bahwasanya seorang wanita dari Aslam bernama Subaiah ditinggal mati oleh suaminya dalam keadaan hamil. Lalu Abu Sanâbil bin Ba'kak melamarnya, namun ia menolak menikah dengannya. Ada yang berkata, "Demi Allahh, dia tidak boleh menikah dengannya hingga menjalani masa iddah yang paling panjang dari dua masa iddah. Setelah sepuluh malam berlalu, ia mendatangi Nabi Shallallahu 'alaihi wa sallam dan Nabi saw bersabda, "Menikahlah!" (HR Al-Bukhâri No. 4906).

Dalil dari sunnah Hadis dari Miswar bin Makhromah:

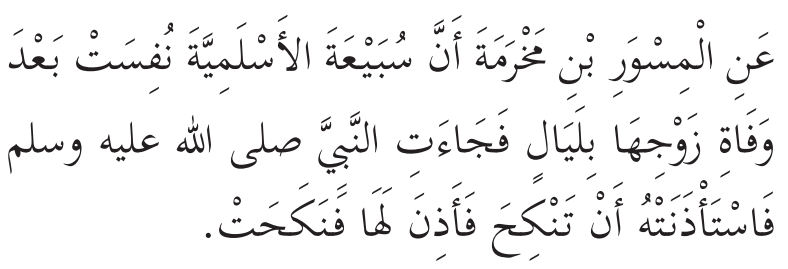

"Bahwasanya Subai'ah Bin Aslamiyah dia melahirkan setelah wafat suaminya beberapa malam setelah itu datang kepada Nabi saw meminta izin kepada Nabi untuk menikah kemudian Nabi mengizinkan,"

\section{Hukum Iddah}

Masa iddah sebenarnya sudah dikenal di masa jahiliyah. Ketika Islam datang, masalah ini tetap diakui dan dipertahankan. Oleh karena itu para Ulama sepakat bahwa 'iddah itu wajib, berdasarkan al-Qur`ân dan Sunnah.` Para ulama sepakat atas wajibnya iddah bagi seorang perempuan yang telah bercerai dengan suaminya. Mereka mendasarkan dengan firman Allah pada surah Al Baqarah ayat 228:

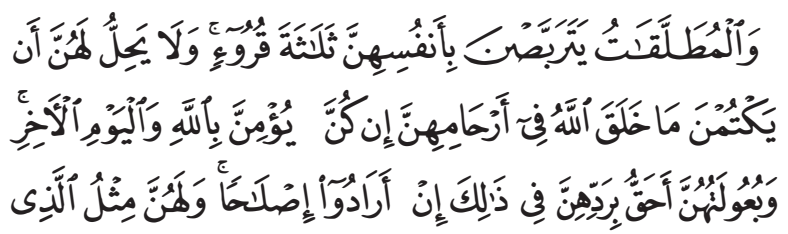

${ }^{7}$ Lihat Mausû'atul Fiqhiyah al-Muyassarah, 2/383 dan Taudhîhul Ahkâm bi Syarhi Bulûghil Maram 5/561 


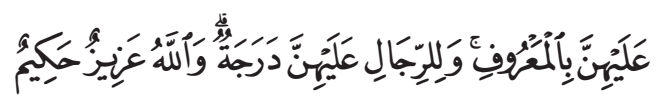

Wanita-wanita yang ditalak handaklah menahan diri (menunggu) tiga kali quru'. Tidak boleh mereka menyembunyikan apa yang diciptakan Allah dalam rahimnya, jika mereka beriman kepada Allah dan hari akhirat. Dan suami-suaminya berhak merujukinya dalam masa menanti itu, jika mereka (para suami) menghendaki ishlah. Dan para wanita mempunyai hak yang seimbang dengan kewajibannya menurut cara yang ma'ruf. Akan tetapi para suami, mempunyai satu tingkatan kelebihan daripada isterinya. Dan Allah Maha Perkasa lagi Maha Bijaksana.

\section{Syarat Wajib dan Rukun Iddah}

\section{a. Syarat Wajib}

Adapun syarat wajibnya adalah terjadinya perceraian antara laki-laki dan perempuan, baik perceraian itu berupa talak raj'i atau talak ba'in ataupun fasakh dengan seluruh sebab-sebabnya atau ditinggalkan setelah nikah yang fasid atau hubungan sebadan karena kesamaran ataupun secara hukum. Hal itu semua adalah setelah terjadinya sebab iddah sesuai dengan apa yang telah dikemukakan. ${ }^{8}$

\section{b. Rukun Iddah}

Rukun iddah meliputi hal-hal yang menjadikan seorang wanita benar-benar sedangkan menjalankan perintah Allah SWT dalam beriddah. Rukun Iddah ada tiga hal yang meliputi keharamannya yaitu: ${ }^{9}$

a) Haram menikah lagi dengan selain suaminya, jika ia beriddah dari talak raj'i

b) Haram keluar dari tempat tinggal atau rumahnya kecuali karena terpaksa

Wajib berkabung dan haram berhias diri, ini adalah pada sebagian dari pada macam-macam iddah bukan seluruhnya.

\footnotetext{
8 Muhammad Fuad, Fiqih Wanita Lengkap (Mengupas Sisi Hukum Wanita Dalam Kehidupan Sehari-Hari), (Jombang:,Penerbit Media, 2007), h. 494.

${ }^{9}$ Muhammad Fuad, Fiqih Wanita Lengkap..., h. 494.
}

\section{Pembagian Masa Iddah}

Banyak sekali ayat Alquran dan hadishadis Nabi saw yang berkaitan dengan iddah, diantaranya adalah:

a. Iddah wanita hamil, maka iddahnya sampai dengan melahirkan, sebagaimana firman Allah Swt dalam surat al-Thalaq ayat 4:

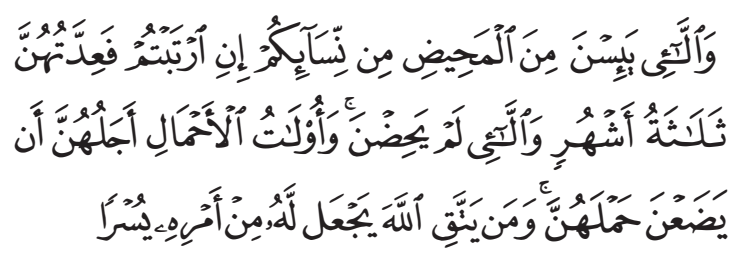

Dan perempuan-perempuan yang tidak haid lagi (monopause) di antara perempuanperempuanmu jika kamu ragu-ragu (tentang masa iddahnya) maka iddah mereka adalah tiga bulan; dan begitu (pula) perempuan-perempuan yang tidak haid. Dan perempuan-perempuan yang hamil, waktu idah mereka itu ialah sampai mereka melahirkan kandungannya. Dan barang siapa yang bertakwa kepada Allah niscaya Allah menjadikan baginya kemudahan dalam urusannya.

Ketentuan waku tunggu bagi janda yang dalam keadaan hamil adalah sampai anaknya lahir. Cara menghitung tenggang waktu tersebut apabila putus perkawinan karena peceraian, maka dihitung sejak jatuhnya putusan pengadilan yang mempunyai kekuatan yang tetap. ${ }^{10}$

Sabda Rasulullah saw:

$$
\begin{aligned}
& \text { عن المسورين مخرمة رضي الله عنه (انّ سبيعة } \\
& \text { الاسلمية نفست بعد وفاة زوجها بليال، فجاءت } \\
& \text { الى النبي ص.م. فاستاءذنته ان تنكح فاذن لها، } \\
& \text { فنكحت) رواه البخارى، واصله في الصحيحين }
\end{aligned}
$$

Dari Miswar putera Makhramah: "Bahwasanya Subaiah Aslamiyah ra melahirkan setelah suaminya meninggal dunia beberapa malam, kemudian ia menghadap Rasulullah dan minta

${ }^{10}$ Hilman Hadikusuma, Hukum Perkawinan Indonesia Menurut Perundangan, Hukum Adat dan Hukum Agama, Penerbit Mandar Maju, Tahun 1990, Bandung, h. 69 
izin untuk kawin, maka Rasulullah mengizinkannya, kemudian ia kawin." (Hadits diriwayatkan oleh Imam Bukhari).

$$
\begin{aligned}
& \text { وفن لفظ (انّا وضعت بعد وفاة زوجها باربعين } \\
& \text { ليلة) وفى لفظ لمسلم قال الزهرى (ولا ارى باءسا } \\
& \text { ان تزوّج وهى فن دمها، غير انّه لا يقربها زوجها } \\
& \text { حتى تطهر) }
\end{aligned}
$$

Dan pada suatu lafadz disebutkan: "sesungguhnya Subaiah melahirkan setelah suaminya meninggal empat puluh hari." Dan pada suatu lafadz pada riwayat Muslim disebutkan: berkata Az Zuhri: "Aku berpendapat tidak ada halangan ia kawin dalam keadaan masih darah nifas, hanya saja suaminya jangan menyetubuhi dulu sebelum ia suci."

b. Iddah Wanita yang Meminta Cerai (Khulu')

$$
\begin{aligned}
& \text { حدّثني عبادة بن الوليدبن عبادة بن الصامت عن } \\
& \text { ربيع بنت معوّذ قال قلت لها حدّثني حديثك قالت } \\
& \text { اختلعت من زوجي ثم جئت عثمان فسألته ماذا }
\end{aligned}
$$

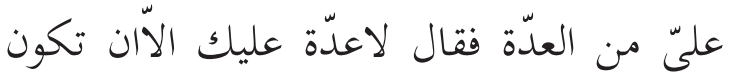

$$
\begin{aligned}
& \text { حديثة عهد به فتمكني حتى تحيضى حيضة قال } \\
& \text { وانا متّبع في ذلك قضاء رسول الله ص.م. في }
\end{aligned}
$$

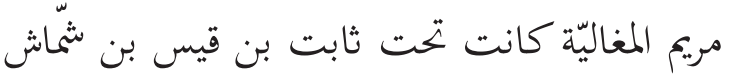

$$
\begin{aligned}
& \text { فاختلعت منه }
\end{aligned}
$$

Menceritakan kepadaku Ubadah Ibnu Walid Ibnu Shamit bertanya pada Rubayyi binti Mu'awidz: "ceritakan kisahmu padaku". Ia berkata: "aku telah meminta cerai dari suamiku". Kemudian aku datang pada Usman dan aku bertanya padanya: "berapa hari masa iddahku." Jawabnya: "tidak ada iddah atasmu, kecuali jika kamu telah bergaul dengan suamimu. Maka sekarang tunggulah hingga kamu haid sekali. Dalam hal ini aku mengikuti keputusan Rasulullah atas diri Maryam Al Maghalibiyah, yang menjadi istri Tsabit Ibnu Qais Ibnu Syamas, dan kemudian ia meminta diceraikan suaminya." c. Iddah Atas Wanita yang Ditinggal Mati Suaminya

Para ulama' mazhab sepakat bahwa iddah wanita yang ditinggal mati suaminya, sedangkan ia tidak hamil adalah empat bulan sepuluh hari baik wanita tersebut sudah dewasa maupun masih anak-anak, dalam usia menopause atau tidak, sudah dicampuri atau belum. ${ }^{11}$ Hal ini didasarkan pada firman Allah Swt dalam Surat Al-Baqarah ayat 234 :

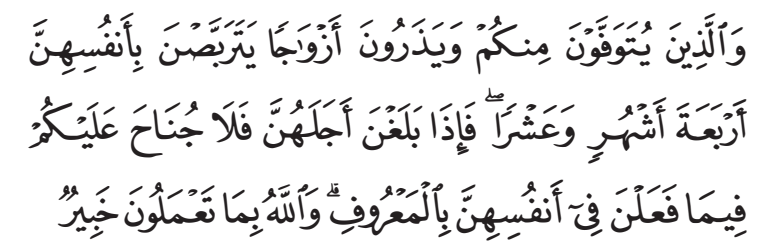

Orang-orang yang meninggal dunia di antaramu dengan meninggalkan isteri-isteri (hendaklah para isteri itu) menangguhkan dirinya (ber'iddah) empat bulan sepuluh hari. Kemudian apabila telah habis iddahnya, maka tiada dosa bagimu (para wali) membiarkan mereka berbuat terhadap diri mereka menurut yang patut. Allah mengetahui apa yang kamu perbuat.

Yang demikian itu apabila wanita tersebut betul-betul terbukti tidak hamil. Akan tetapi apabila ia diduga hamil atau kemungkinan sedang hamil, maka di harus menunggu sampai dia melahirkan anaknya atau diperoleh kepastian bahwa dia betul-betul tidak hamil. Demikian pendapat mayoritas ulama mazhab.

Putusnya perkawinan karena kematian tenggang waktunya dihitung sejak suaminya meninggal, ketentuan tenggang waktu tersebut tidak berlaku bagi janda yang putus perkawinan karena perceraian, apabila antara janda tersebut dengan bekas suaminya belum pernah terjadi hubungan kelamin. ${ }^{12}$

\footnotetext{
${ }^{11}$ Muhammad Jawad Mughniyah, Fiqh Lima Mazhab Edisi Lengkap, h. 469.

12 Hilman Hadikusuma, Hukum Perkawinan Indonesia Menurut Perundangan, Hukum Adat dan Hukum Agama, Penerbit Mandar Maju, Tahun 1990, Bandung, h. 69
} 


$$
\begin{aligned}
& \text { عن زينب بنت ام سلمة قالت امّ حبيبة سمعت } \\
& \text { رسول الله صلى الله عليه وسلم يقول لا يحلّ لامرأة } \\
& \text { تؤمن بالله واليوم الاخر تحدّ على ميت فوق ثلاثة } \\
& \text { أيام الا على زوج اربعة اشهر وعشرا }
\end{aligned}
$$

Dari Zainab binti Ummu Salamah dari Ummu Habibah ra. Berkata: "aku mendengar Rasulullah saw bersabda:" tidak dihalalkan bagi seorang wanita yang beriman kepada Allah dan hari akbir, berkabung atas orang yang mati lebih dari tiga hari, kecuali atas kematian suaminya, maka masa berkabungnya selama empat bulan sepuluh hari."

d. Iddah Atas Wanita yang Ditinggal Mati Suaminya Sebelum Terjadi Senggama

Iddah wanita atau isteri yang belum dicampuri, baginya tidak ada iddah. Hal ini berdasarkan firman Allah Swt dalam surat alAhzab surat ke-33 ayat 49 berikut:

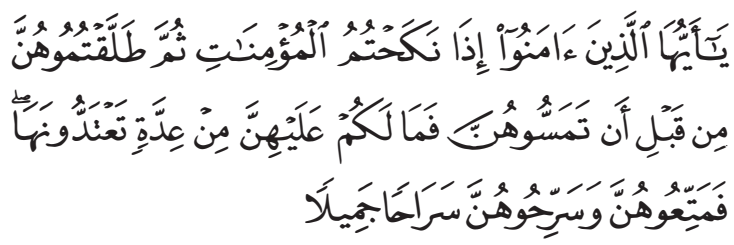

"Hai-hai orang-orang yang beriman, apabila menikahi wanita-wanita yang beriman, kemudian kamu ceraikan mereka sebelum kamu mencampurinya, maka sekali-kali tidak wajib atas mereka iddah bagimu yang kamu minta menyempurnakannya. Maka berilah mereka mut'ah dan lepaskanlah mereka itu dengan cara yang sebaik-baiknya.

Di samping itu, dijelaskan juga dalam hadis Nabi saw:

$$
\begin{aligned}
& \text { عن عبراهيم عن علقمة عن ابن مسعود انه سئل عن }
\end{aligned}
$$

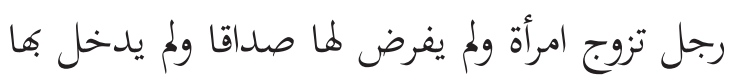

$$
\begin{aligned}
& \text { حتى مات قال ابن مسعود لما مثل صداق نسائها لا لا }
\end{aligned}
$$

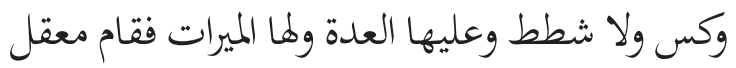

$$
\begin{aligned}
& \text { بن سنان الاشجعي فقال قضى فينا رسول الله ص م }
\end{aligned}
$$



$$
\begin{aligned}
& \text { مسعود رضى الله عنه }
\end{aligned}
$$

"Dari Ibrahim dari Alqamah berkata: "Ketika Ibnu Mas'ud ditanya tentang seseorang yang menikahi wanita, kemudian ia mati sebelum memberikan mas kawin pada istrinya dan juga belum bersenggama dengannya. Jawab Ibnu Mas'ud: Istrinya tetap berhak mendapatkan mas kawin, tidak boleh kurang atau lebih, dan atasnya berlaku iddah serta ia berhak mendapat warisan". Maka berdirilah Ma'qil ibnu Sinan Al Asyjäi dan berkata: "Rasulullah saw telah memutuskan masalah Barwa' binti Wasyq, sebagaimana yang putuskan. Ia adalah seorang wanita kaum kami." Karena itu Ibnu Mas'ud menjadi senang."

\section{Faktor-Faktor Penyebab Iddah}

Pada masa jahiliyah dikalangan isteri-isteri yang tidak jujur sering tidak mengatakan bahwa dirinya telah hamil. Setelah iddahnya habis dia kawin lagi dengan laki-laki lain, tidak lama setelah kawin lahir anaknya terjadilah perselisihan dan pertengkaran antara suami isteri. Apabila mantan suami tidak mengakui bahwa itu anaknya, maka teraniayalah bayi yang tidak besalah itu disebabkan ibunya tidak jujur ketika masih dalam iddah. Ada pula terjadi masa itu isteri tidak mau berterus terang bahwa iddahnya sudah habis, dia mengatakan masih dalam haid. Maksud dia berbohong itu agar suaminya tetap memberi belanja kepadanya selama ia tetap dalam iddah, maka turunlah ayat 228-232 surat Al-Baqarah yang melarang isteri yang dicerai menyembunyikan apa yang terjadi dalam rahimnya. Selama perempuan yang ditalak itu masih dalam iddah, maka suami boleh rujuk, itulah yang lebih baik jika niat rujuknya ingin membina kembali rumah tangganya yang baik. Cukuplah waktu iddah itu bagi suami untuk berpikir apakah ia akan rujuk kembali (lebih-lebih sudah ada anak) atau akan bercerai. Tetapi kalau rujuk itu bukan didorong oleh maksud yang baik yakni hanya untuk membalas dendam atau untuk menyusahkan dan menyakiti isteri, maka perbuatan seperti itu dilarang Allah Swt dan itu perbuatan zalim terhadap perempuan. 
Talak yang dijatuhkan kepada isteri seperti ini bernama talak raj'i yaitu talak yang masih boleh rujuk sebelum habis masa iddah. ${ }^{13}$

Iddah disebabkan dua faktor. Pertama, karena ditinggal mati suami, kedua, karena dicerai suami. Dan kondisi wanita yang sedang iddah dibagi dua; hamil dan tidak hamil. Bagi wanita yang sedang hamil, iddahnya akan selesai dengan sebab melahirkan, baik melalui persalinan normal ataupun dengan jalan sesar, karena tujuan utamanya adalah keluarnya bayi. ${ }^{14}$

\section{Hak dan Kewajiban Suami Selama Masa Iddah dan Tujuan Iddah}

Fuqaha sepakat bahwa wanita yang diceraikan dengan talak raj'i berhak memperoleh nafkah sepenuhnya yang wajib atas suaminya yang menceraikannya selama masa iddahnya, karena hubungan perkawinan mereka berdua masih sah secara hukum, juga karena ia tertahan disebabkan suaminya. Adapun perempuan yang diceraikan secara talak ba'in, maka mazhab Hanafi berpendapat bahwa selama masa iddahnya ia berhak mendapatkan nafkah penuh yang wajib atas suaminya yang menceraikannya. Sedangkan mazhab Syafe'i berpendapat bahwa ia berhak mendapat tempat tinggal saja yang wajib atas suami yang menceraikannya. Ia tidak berhak nafkah kecuali itu apabila ia tidak hamil. Namun apabila ia sedang hamil, maka suaminya berkewajiban memberikan nafkah kepadanya secara penuh sebagaimana pendapat mazhab Hanafi. ${ }^{15}$

Adapun untuk isteri yang beriddah karena kematian suaminya, maka nafkah tidak wajib untuknya sesuatu dari nafkah secara mutlak, karena ia tidak memerlukannya disebabkan mendapatkan warisan, hal ini sesuai dengan

${ }^{13}$ Kementerian Agama RI Direktorat Jenderal Bimbingan Masyarakat Islam Direktorat Urais dan Pembinaan Syari'ah, $A l$ Qur'an dan Tafsirnya, Dicetak PT. Sinergi Pustaka Indonesia, Tahun 2012, h. 337

${ }_{14}$ Asy-Syarwani \& al-'Abbadi, Syarh Tuhfatul Mubtaj Juz VIII, h. 106

${ }^{15}$ Muhammad Fuad, Fiqih Wanita Lengkap (Mengupas Sisi Hukum Wanita Dalam Kehidupan Sehari-Hari), h. 511 kesepakatan fuqaha'. Suami berkewajiban untuk memberikan nafkah kepada isterinya sebagaimana telah dijelaskan, selama isteri berada dalam rumah suaminya. Namun apabila ia keluar dari rumah itu tanpa memperoleh izin darinya dan tanpa sebab yang dibenarkan menurut syari'at, maka isteri tersebut telah berbuat nusyuz. Sedangkan isteri nusyuz nafkahnya gugur, tidak seperti isteri yang tidak nusyuz. ${ }^{16}$

Suami berkewajiban menanggung nafkah isteri selama masa iddah menurut kemampuannya yang ditetapkan oleh Pengadilan Agama. ${ }^{17}$ Menurut KH. Azhar Basyir, MA dalam bukunya Hukum Perkawinan Islam. Yogyakarta: UII Press. Cet. 19. Tahun 1999, iddah diadakan dengan tujuan sebagai berikut:

1. Untuk menunjukkan betapa pentingnya masalah perkawinan dalam ajaran Islam.

2. Peristiwa perkawinan yang demikian penting dalam hidup manusia itu harus diusahakan agar kekal.

3. Dalam perceraian karena ditinggal mati, iddah diadakan untuk menunjukkan rasa berkabung atas kematian suami bersamasama keluarga suami.

4. Bagi perceraian yang terjadi antara suami istri yang pernah melakukan hubungan kelamin, iddah diadakan untuk meyakinkan kekosongan rahim.”

\section{Hikmah disyari'atkan Iddah}

Jangka waktu dalam hukum Islam disebut "Iddah" tujuannya adalah untuk mengetahui apakah janda itu ketika bercerai (cerai mati atau cerai hidup) tidak dalam keadaan mengandung atau mengandung. ${ }^{18}$ Hikmah disyariatkannya iddah, diantaranya:

\footnotetext{
${ }^{16}$ Muhammad Fuad, Fiqih Wanita Lengkap (Mengupas Sisi Hukum Wanita Dalam Kehidupan Sehari-Hari), h. 512

${ }^{17}$ Diterbitkan oleh Proyek Peningkatan Sarana Keagamaan Islam, Zakat dan Wakaf Direktorat Jenderal Bimas Islam dan Urusan Haji, Pedoman Figh Munakahat, h. 35

18 Hilman Hadikusuma, Hukum Perkawinan Indonesia Menurut Perundangan, Hukum Adat dan Hukum Agama, Penerbit Mandar Maju, Tahun 1990, Bandung, h. 69
} 
1. Untuk memastikan kosongnya rahim dari janin, sehingga tidak tercampurnya nasab

2. Untuk memberikan waktu bagi suami yang mencerai istrinya untuk rujuk apabila dia menyesal jika pada talak raj'i

3. Menjaga hak seorang wanita/istri yang hamil apabila terjadi talak pada saat hamil.

4. Untuk memperlihatkan betapa besarnya dan terhormatnya permasalahan pernikahan dan memberikan pemahaman bahwa akad nikah mengungguli akad-akad yang lainnya.

5. Memperlihatkan rasa sedih karena baru ditinggal mati suami. Jadi kalau wanita menahan diri untuk tidak berdandan, hal itu membuktikan kesetiaannya kepada suaminya yang telah meninggal. ${ }^{19}$

Adapun hikmah yang lain: Pertama: untuk mengetahui bersihnya rahim perempuan tersebut dari dari bibit yang ditinggalkan mantan suaminya. Hal ini disepakati oleh ulama. Pendapat ulama pada saat itu didasarkan pada dua alur pikir:

1. Bibit yang ditinggal oleh mantan suami dapat berbaur dengan bibit yang orang yang mengawininya untuk menciptakan satu janin dalam perut perempuan tersebut. Dengan pembaruan itu diragukan anak siapa sebenarnya dikandung oleh perempuan tersebut. Untuk menghindarkan perbauran bibit itu, maka perlu diketahui atau diyakini bahwa sebelum perempuan itu kawin lagi rahimnya bersih dari peninggalan mantan suaminya.

2. Tidak ada cara untuk mengetahui apakah perempuan yang baru berpisah dari suaminya mengandung bibit dari mantan suaminya atau tidak kecuali dengan datangnya beberapa kali haid dalam masa itu. Untuk itu diperlukan masa tunggu. Alur pikir pertama tersebut di atas tampaknya waktu ini tidak relevan lagi karena sudah diketahui bahwa bibit yang akan menjadi

19 lihat Mulakhos Fiqhiy, Syaikh Al-Fauzan, h. 419-420, Fiqih Muyasar, h. 317 janin hanya dari satu bibit dan berbaurnya beberapa bibit dalam rahim tidak akan mengaruhi bibit yang sudah memproses menjadi janin itu. Demikian pula alur pikir kedua tidak relevan lagi karena waktu ini sudah ada alat yang canggih untuk mengetahui bersih atau tidaknya rahim perempuan dari mantan suaminya. Meskipun demikian, iddah tetap diwajibkan dengan alasan di bawah ini.

Kedua, untuk ta'abbud, artinya semata untuk memenuhi kehendak dari Allah meskipun secara rasio kita mengira tidak perlu lagi. Contoh dalam hal ini, umpanya perempuan yang kematian suami dan belum digauli oleh suaminya itu, masih tetap wajib menjalani masa iddah, meskipun dapat dipastikan bahwa mantan suaminya tidak meninggalkan bibit dalam rahim istrinya itu.

Adapun hikmah yang dapat diambil dari ketentuan iddah itu adalah agar suami yang telah menceraikan istrinya itu berpikir kembali dan menyadari tindakan itu tidak baik dan menyesal atas tindakannya itu. Dengan adanya iddah dia dapat menjalin kembali hidup perkawinan tanpa harus mengadakan akad baru.

Disyari'atkannya iddah memiliki beberapa makna dan hikmah, diantaranya $:{ }^{20}$

1. Untuk mengetahui kebersihan rahim agar jangan sampai terjadi dua benih menyatu dalam satu rahim, sehingga akan mengakibatkan kacaunya keturunan.

2. Menghargai pentingnya perkawinan dan meninggikan derajatnya serta menampakkan kemuliannya.

3. Memperlama kesempatan rujuk bagi suami yang menjatuhkan talak, barangkali ia menyesali perbuatannya, sehingga ada kemungkinan baginya untuk rujuk.

4. Menuntaskan hak suami dan menampakkan

${ }^{20}$ Syaikh Abu Malik Kamal bin As-Sayyid Salim, Panduan Beribadah Khusus Wanita (Menjalankan Ibadah Sesuai Tuntunan Al-Qur'an dan As-Sunnah), Penerbit Almahira Jakarta, Cet. 1 Tahun 2007, h. 525-526 
dampak kehilangannya yang tercermin pada larangan berhias dan bersolek, karena itu disyariat wanita yang diceraikan agar berkabung lebih lama dari pada terhadap orang tua dan anak.

5. Kehati-hatian untuk hak suami, kemaslahatan untuk isteri dan hak anak-anaknya disamping memenuhi hak Allah. Jadi dalam iddah itu ada empat pihak yang mendapatkan hak.

\section{Penutup}

Adapun yang menjadi kewajiban seorang suami dalam masa iddah (talak raj'i) yaitu memberikan tempat tinggal dan nafkah kepada istrinya. Dan jika dia punya seorang anak maka dia juga berkewajiban membiayai anaknya. Sedangkan yang menjadi hak dan kewajiban seorang istri dalam masa iddah ialah:

1. Tidak boleh dipinang oleh laki-laki lain, baik secara terang-terangan maupun dengan cara sindiran. Namun bagi wanita yang ditinggal mati suaminya dikecualikan bahwa ia boleh dipinang dengan sindiran.

2. Dilarang keluar rumah menurut jumhur ulama fikih selain mazhab Syafi'i apabila tidak ada keperluan mendesak, seperti untuk memenuhi kebutuhan hidup sehari-harinya.

3. Berhak untuk tetap tinggal dirumah suaminya selama menjalani masa iddah.

4. Wanita yang berada dalam iddah talak raj'i terlebih lagi yang sedang hamil, berhak mendapatkan nafkah lahir dari suaminya. Bagi wanita yang ditinggal mati suaminya tentu tidak lagi mendapatkan apa-apa kecuali harta waris, namun berhak untuk tetap tinggal di rumah suaminya sampai berakhirnya masa iddah.

5. Wanita yang berada dalam iddah talak raj'i ia berhak mendapatkan harta waris dari suaminya yang wafat, sedangkan wanita yang telah ditalak tiga tidak berhak mendapatkanya.

\section{Pustaka Acuan}

Anwar, Moh., Figh Islam (Muamalah, Munakahat, Faroid dan Jinayah Beserta Kaidah-Kaidah Hukumnya), Subang: t.pn.,.1988, Cet. ke-2.

Basyir, Azhar, Hukum Perkawinan Islam, Yogyakarta: Penerbit UII Press, 1999, Cet. ke-19.

Dahlan, Abdul Aziz (ed) Ensiklopedi Hukum Islam, Jilid II, Jakarta: Ihktiar Baru Van Hoeve, 1996.

Ghundur, Ahmad al-, al-Thalaq al-syariat alIslamiyyah wal al-Qanun, Mesir: Dar alMa’arif, 1997

Hadikusuma, Hilman, Hukum Perkawinan Indonesia Menurut Perundangan, Hukum Adat dan Hukum Agama, Penerbit Mandar Maju, Tahun 1990

Kementerian Agama RI Direktorat Jenderal Bimbingan Masyarakat Islam Direktorat Urais dan Pembinaan Syariah, Al-Qur'an dan Tafsirnya, Dicetak PT. Sinergi Pustaka Indonesia, Tahun 2012

Mausû'atul Fiqhiyah al-Muyassarah, 2/383 dan Taudhîhul Ahkâm bi Syarhi Bulûghil Maram $5 / 561$

Mughniyah, Muhammad Jawad, Figh Lima Mazhab Edisi Lengkap.

Muhammad Fuad, Fiqih Wanita Lengkap (Mengupas Sisi Hukum Wanita Dalam Kehidupan Sehari-Hari), Penerbit Media, Jombang, 2007.

Proyek Peningkatan Sarana Keagamaan Islam, Zakat dan Wakaf Direktorat Jenderal Bimas Islam dan Urusan Haji, Pedoman Figh Munakahat, Jakarta, Tahun 1999/2000.

Proyek Peningkatan Sarana Keagamaan Islam, Zakat dan Wakaf Direktorat Jenderal Bimas Islam dan Urusan Haji, Pedoman Fiqh Munakahat.

Salim, Syaikh Abu Malik Kamal bin AsSayyid, Panduan Beribadah Khusus Wanita (Menjalankan Ibadah Sesuai Tuntunan AlQur'an dan As-Sunnah), Jakarta: Penerbit Almahira, 2007, Cet. ke-11. 
Segaf, Sayyid Alawi bin Sayyid Ahmad al-, Tarsyihul Mustafidin, Beirut, Darul Fikr, t.th.

Syarwani, al, \& al-'Abbadi, Syarh Tuhfatul Muhtaj Juz VIII
Tahfidz, Ahsin W. al-, Kamus Ilmu Al-Qur'an, Penerbit Amzah, 2006, Jakarta 